\title{
Benefits of low-tar smokes just a pipe dream
}

\section{Corie Lok, Washington}

Smokers puffing on low-tar cigarettes may be deluding themselves, according to the US Institute of Medicine (IoM). Research has yet to show that these modified cigarettes are any safer than their conventional counterparts, a report by the IoM concludes.

In its study, the IoM found no evidence that using low-tar cigarettes reduces a smoker's exposure to carcinogens. And even if these cigarettes do lower the amount of carcinogens inhaled, there is also no evidence that this would necessarily reduce the smoker's susceptibility to disease.

"No one knows whether decreased exposure translates into decreased risk for disease," says Stuart Bondurant, medical professor at the University of North Carolina, Chapel Hill, and chair of the IoM committee that studied the problem.

The independent panel made its assessment of the harm reduction potential of lowtar cigarettes and other nicotine products at the request of the US Food and Drug Administration (FDA). Its report, "Clearing the Smoke: Assessing the Science Base for Tobacco Harm Reduction", was published last week.

Cigarettes that are low in tar and nicotine raise a public health concern because they may use implied but unsubstantiated safety claims to keep smokers hooked on tobacco and attract new users, the report says. And there is no guarantee that the products reduce harmful exposure because the smokers tend to suck harder and smoke more frequently to maintain their nicotine levels.

The IoM panel found that more research is needed to establish whether there is a link between exposure reduction and harm reduction. Such research, it says, could improve understanding of dose-response relationships of specific smoke components, develop and validate biomarkers that link smoke exposure to disease risk, and explore the epidemiology of smoking and health.

The report also suggests preclinical studies to determine harmful smoke components and their pathogenic effects. For example, new genomic and proteomic technologies could be used to look at the effect of tobacco exposure on gene translation and expression in disease.

FDA-approved nicotine products were also examined by the panel. These include patches, sprays and chewing gum, which deliver pure nicotine at low doses. The products are approved only for short-term use to help smokers quit the habit, but research has not established long-term safety for those smokers using them to continue to get low levels of nicotine, the report says.

The report recommends new regulations requiring manufacturers to disclose ingredient, exposure and experimental data to back

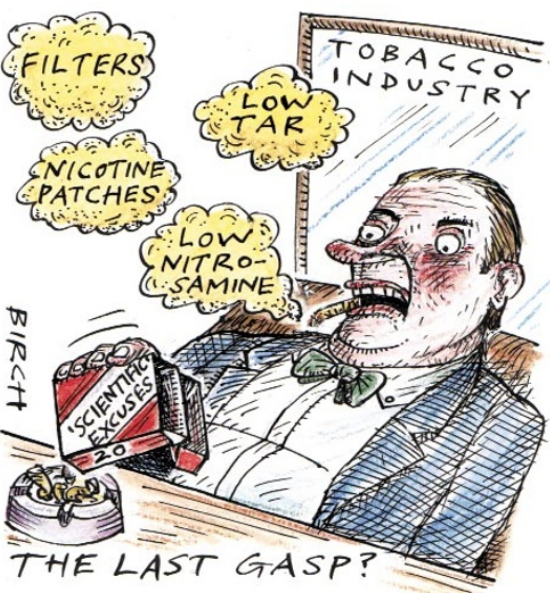

up any risk-reduction claims. But it did not suggest a particular agency to take on this regulatory task. It also emphasizes the need for a national, comprehensive surveillance system to monitor product characteristics and usage patterns.

Although both the National Institutes of Health and the tobacco industry have conducted some research into the health effects of the products covered in the report, the field is "in its infancy," according to Peter Shields, a panel member and associate director of Georgetown University's Lombardi Cancer Center.

http://books.nap.edu/catalog/10029.html

\section{Museum suffers spiritual cramps over Mendel's work}

\section{David Adam}

With the ink on the published human genome barely dry, an unseemly row has broken out at the monastery where Gregor Mendel founded the study of genetics almost 150 years ago. The argument is over the commemoration of his life and work.

Mendel first entered the monastery at Brno in the Czech Republic in 1843, and was elected abbot in 1868. His study there of how pea plant characteristics passed between generations revealed the fundamental laws of genetic inheritance.

Now staff at a small museum that is situated in the monastery say that the current abbot, Lukas Evzen Martinec, is threatening to evict them because their museum places too much emphasis on the scientific aspects of Mendel's life. The abbot, they say, wants a new exhibition of Mendel's life that will reflect his religious beliefs as well as his scientific interests.

Martinec confirms that he is unhappy with the low religious content of the museum's display. But he says that his decision to replace it is part of wider plans to

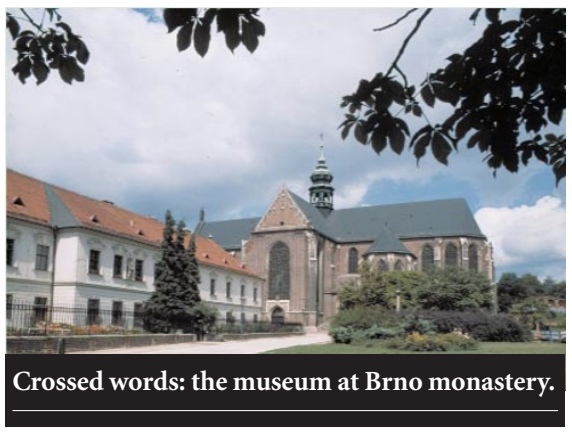

develop a new, extended museum. He adds that he gave the existing museum's directors more than a year to come up with a proposal for a new exhibition, and that, having failed to do so, they are mounting a "disinformation campaign" against him.

"Communication with the abbot is nonexistent, but we never believed he would go this far," says Anna Matalova, director of the museum, the Mendelianum.

The museum's display was closed earlier this year and the exhibition hall is due to be refurbished. "The abbot refused to promise that the Mendelianum would be returned to the exhibition hall after the reconstruction," says Matalova.

The museum also has archives and offices in the monastery, but Martinec recommended in a recent letter that they "consider immediate relocation". The staterun museum rents the rooms from the monastery, but pays less than a private company would.

Martinec says that the exhibition hall has been "neglected" after " 35 years without adequate maintenance". He is also angry that the museum's owners have not uncovered religious motifs that were hidden during the communist days. He is now preparing a replacement exhibition with help from local university researchers.

Emil Palecek, a molecular biologist at the Czech science academy's Institute of Biophysics in Brno, has seen the abbot's plans and predicts that the new exhibition will be an improvement. He says the refurbishment is an important part of a plan to transform that part of the monastery into a conference centre, and perhaps even a bioinformatics institute. 